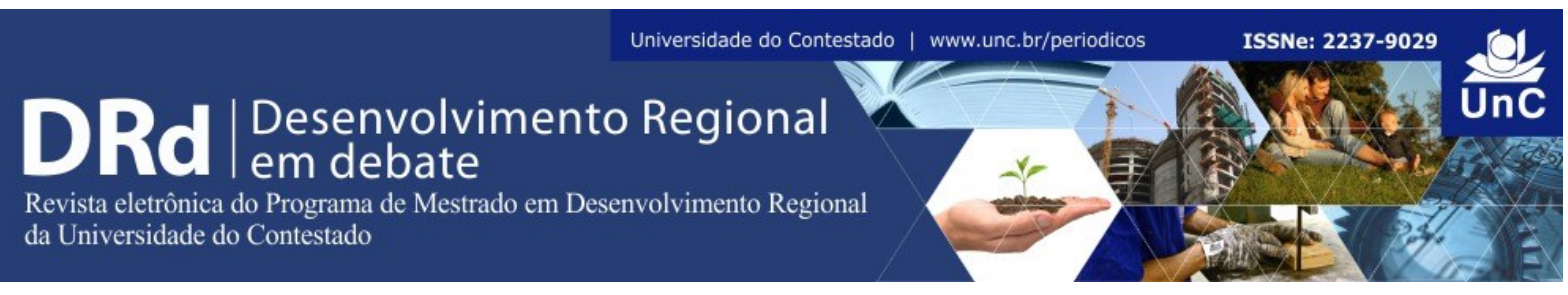

\title{
A ABORDAGEM DA VIOLÊNCIA PELA MÍDIA NAS PEQUENAS CIDADES DA REGIÃO NORTE CENTRAL DO PARANÁ
}

\author{
Pedro Henrique Carnevalli Fernandes ${ }^{1}$
}

\begin{abstract}
RESUMO
A violência se disseminou pela sociedade brasileira, se tornando um discurso comum na mídia. Por outro lado, a construção do imaginário de cidades inseguras é resultado de uma produção de grupos de agentes, inclusive a própria mídia. Assim, contemplar os fatos divulgados pela mídia, em correspondência com os resultados empíricos, gera, concomitantemente, situações antagônicas: propagadora do medo, da insegurança e da violência versus difusora de casos não contemplados pelos órgãos estatais. Por isso, o objetivo principal deste artigo é compreender a abordagem da violência pela mídia nas pequenas cidades da região Norte Central paranaense e a partir disso comparar com as taxas de homicídios. Os procedimentos metodológicos utilizados para a construção deste artigo foram: levantamento bibliográfico de assuntos pertinentes ao tema, levantamento de dados secundários das pequenas cidades da região Norte Central paranaense, levantamento de notícias em um jornal regional, levantamento das taxas de homicídios dos municípios polarizados por pequenas cidades da região Norte Central paranaense e realização da redação deste artigo. Os resultados revelaram casos em que a mídia destaca espaços não contemplados pelos órgãos públicos de estatísticas do Paraná e, concomitantemente, casos em que a mídia produz um simulacro ou simplesmente ignora os espaços das pequenas cidades, mesmo elas possuindo altas taxas de homicídios.
\end{abstract}

Palavras chaves: Geografia Humana. Jornal. Homicídio. Pequena Cidade.

\section{THE APPROACH TO MEDIA VIOLENCE IN SMALL TOWNS IN THE NORTH CENTRAL OF PARANÁ}

\begin{abstract}
Violence spread throughout Brazilian society, becoming a common discourse in the media. On the other hand, the construction of the imaginary of insecure cities is the result of a production of groups of agents, including the media. Therefore, to contemplate the facts published by the media, in correspondence with the empirical results, it generates, concomitantly, antagonistic situations: propagator of fear, insecurity and violence versus diffuser of cases not contemplated by state organs. Therefore, the main objective of this paper is to understand the approach of violence by the media in the small towns of the North Central of Paraná and from this compare with the homicide rates. The methodological procedures used for the construction of this paper were: bibliographic survey of subjects pertinent to the

\footnotetext{
${ }^{1}$ Doutor em Geografia pela Universidade Estadual de Maringá (UEM). Docente do Colegiado de Geografia da Universidade Estadual do Norte do Paraná (Uenp). Editor da Revista Geoingá. Cornélio Procópio, Paraná. Brasil. E-mail: profpedrofernandes@gmail.com
}

DRd - Desenvolvimento Regional em debate (ISSNe 2237-9029)

v. 7, n. 2, p. 138-157, jul./dez. 2017. 
theme, survey of secondary data of the small towns of the North Central of Paraná, survey of news in a regional newspaper, survey of homicide rates of small towns of the North Central of Paraná and writing this paper. The results revealed cases in which the media highlight spaces not covered by the public statistics agencies of Paraná and, concomitantly, cases in which the media produces a simulacrum or simply ignores the spaces of small towns, even with high homicide rates.

Keyword: Human Geography. Newspaper. Homicide. Small town.

\section{INTRODUÇÃO}

A violência e a insegurança, contextualizadas em uma visão mais geral, têm encontrado terra fértil para se disseminar na sociedade contemporânea, inclusive a brasileira. Em suma, tornou-se um discurso presente cotidianamente na mídia, nos domicílios e na universidade. Apesar disso e de os medos estarem presentes em todos os lugares analogamente ao fenômeno de globalização -, eles assumem características diferentes em cada pessoa - ou grupos sociais - e na materialização em cada espaço, influenciando, a partir disso, hábitos e costumes de vida distintos entre as pessoas.

Nesse sentido, a construção do imaginário das cidades inseguras é resultado de uma produção articulada e não aleatória de grupos de agentes produtores de discursos e de imagens de insegurança: i) a mídia; ii) os promotores imobiliários; iii) as empresas que oferecem equipamentos e serviços de segurança; iv) os políticos; e v) os próprios citadinos (MAGRINI, 2013). Neste artigo, focaliza-se o primeiro agente, a mídia.

As cidades, nessa lógica de produção, dependem das "[...] relações diretas entre as pessoas e os grupos que compõem a sociedade" (LEFEBVRE, 2001, p. 52), seja quanto às relações entre indivíduos e grupos, seja quanto às relações regidas por instituições, como a mídia, a Igreja e o Estado. O que Lefebvre (2001) transmite é que a produção efetiva da cidade é muito mais do que uma produção de objetos, uma simples ocasião de lucro. Ela é uma produção e reprodução de seres humanos por seres humanos, onde "[...] viver numa cidade significa viver junto" (BAUMAN, 2009, p. 74). Para isso, é indispensável a sociabilidade.

Atualmente, o espaço urbano é o principal local das relações sociais. A consolidação desse espaço, em substituição ao rural, ocorreu de maneira muito rápida, em curto período de tempo. Segundo Endlich (2006, p. 161), “[...] a acelerada transitoriedade faz com que a condição de vida produzida no âmbito capitalista seja profundamente alterada no curso de uma geração". Segundo a mesma autora, não há um modelo completo de reprodução da vida e de valores que persista entre gerações subsequentes. Tal mudança brutal no modo de vida é amplificada com o advento das novas tecnologias, levando muitos autores a afirmarem que o ser humano não está preparado para a vida urbana.

Por isso, o objetivo principal deste artigo é compreender a abordagem da violência pela mídia, como fatos narrados, nas pequenas cidades da região Norte Central paranaense. Os objetivos específicos são: discorrer acerca da base teórica desta pesquisa, tais como: mídia 
e violência e demonstrar a realidade dos municípios que compõem a região Norte Central paranaense, sobretudo pelos fatos narrados pela mídia e as taxas de homicídios.

A partir disso, este artigo contempla os fatos divulgados pela mídia, em correspondência com os resultados empíricos, que acabam atuando, ao mesmo tempo, com papéis antagônicos: propagadora do medo, da insegurança e da violência (colaborando para a indústria do medo) e difusora de casos não contemplados pelos órgãos estatais (colaborando com realidades empíricas abandonadas). Assim, considera-se que as notícias não são os fatos, mas as interpretações deles (SANTOS, 1999), especialmente em temas polêmicos. Por outro lado, ainda que marcado por ideologia, com a ausência de outras fontes, elas podem ser a forma possível de tomar conhecimento dos próprios fatos.

Em uma sociedade caracterizada pela presença de múltiplas formas de violência, a violência representada pela mídia é, ao mesmo tempo, uma resposta a uma violência real e um estímulo a outra nova violência (GOES; SPOSITO, 2014). Já segundo Feghali, Mendes e Lemgruber (2006, p. 13), a impunidade e as injustiças "[...] fomentam o ilícito, o crime e a desesperança. A sensação de impotência diante desse quadro, agravado pelo papel equivocado da mídia, propicia a "cultura do medo"".

Em contrapartida, os dados oficiais disponibilizados pelos órgãos públicos, em sua maioria, não contemplam a realidade urbana em totalidade. No caso específico do Estado do Paraná, os dados disponibilizados pelo Governo Estadual para os municípios são recentes e abordam apenas os homicídios (não contemplando dados de furtos, roubos, sequestros, entre outras violências).

Os procedimentos metodológicos utilizados para a construção deste artigo foram: levantamento bibliográfico de assuntos pertinentes ao tema, levantamento de dados secundários das pequenas cidades que compõem a região Norte Central paranaense, levantamento de notícias em um jornal, com período de um de agosto de 2001 a um de agosto de 2011, totalizando uma série temporal de dez anos, levantamento das taxas de homicídios dos municípios polarizados por pequenas cidades que compõem a região Norte Central paranaense a partir da referência de Fernandes (2017) e realização da redação deste artigo.

Quanto ao debate teórico sobre o método, este artigo ancora-se, teoricamente, em Benevides (1983), Santos (1999), Lefebvre (2001) e Chaui (2006). Já acerca da análise dos dados, o artigo contempla uma perspectiva quanti-qualitativa de análise, apresentando dados quantitativos que articulados e analisados à luz da base teórica demonstram cenário qualitativos acerca da realidade da região Norte Central paranaense, apresentada na Figura 1. 
Figura 1. Mesorregião Norte Central paranaense. Municípios e sedes

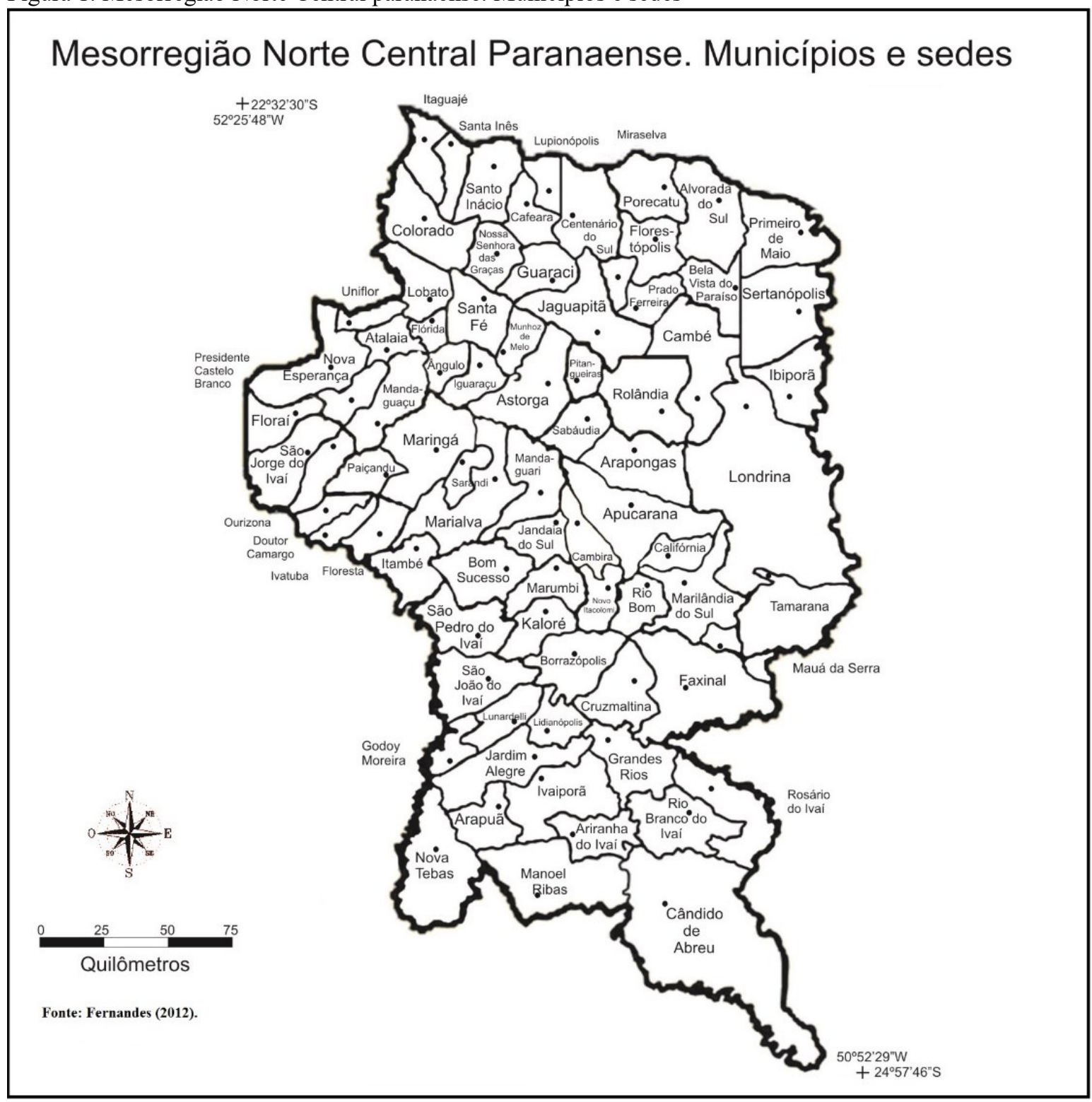

Fonte: Adaptado de Fernandes (2012)

A região Norte Central paranaense, recorte espacial deste artigo, é composta por 79 municípios, correspondendo, segundo o IBGE (2010), a uma área de pouco mais de 12 mil $\mathrm{km}^{2}$ (12\% do Paraná) e a 2.037.151 habitantes (19\% da população do Estado). A abordagem regional atende à preocupação de não tratar localidades isoladas como se fossem exclusivas. Os problemas aqui levantados atingem com maior intensidade algumas localidades, mas como tendência observa-se que as localidades da região e do Paraná, de forma geral, são atingidas igualmente.

O Norte do Estado do Paraná se configura como uma região marcada por densa rede urbana, com muitas pequenas cidades. A maioria delas apresenta problemas relacionados a serviços de saúde, educação, infraestrutura, geração de emprego e renda, segurança, entre outros serviços importantes para o bem-estar coletivo. A região apresenta algumas peculiaridades que a torna especialmente relevante para o estudo de dinâmicas que afetam as 
pequenas cidades, já que vivenciaram, em pouco espaço de tempo, transformações econômicas e socioespaciais que provocaram, inicialmente, uma imensa chegada de moradores (motivando inúmeras consolidações municipais) e, depois, uma imensa saída da população, diminuindo a densidade, a centralidade dos núcleos urbanos.

Nesse sentido, o desenvolvimento do artigo está estruturado da seguinte forma, além da introdução (parte 1) e das considerações finais (parte 5): a segunda parte apresenta os fatos narrados pela mídia à luz da base teórica crítica, ou seja, demonstrar como os meios de comunicação abordam e divulgam os fatos marcados pela violência, sem confundir a visibilidade do "fenômeno" com a espetacularização promovida pela mídia; na terceira parte utiliza-se de notícias de um jornal impresso, a partir de um olhar crítico, para ajudar a compreender a realidade de um determinado local ou da região (Norte Central paranaense); finalmente, a parte quatro destaca a violência pelas taxas de homicídios articuladas com os fatos divulgados pela mídia na região Norte Central paranaense.

\section{OS FATOS NARRADOS PELA MÍDIA}

Com o avanço do sistema capitalista, surgem ícones e indicadores do modernismo, como a televisão, em um primeiro momento, e a internet, mais recentemente. Para Curbet (2010), a televisão, após a segunda metade do século XX, se consolidou como uma instituição central da modernidade. Atualmente, os dados mais recentes, divulgados pelo IBGE (2016), mostram que a televisão está presente em $97,1 \%$ dos domicílios brasileiros, sendo que $40 \%$ deles possuíam sinal digital aberto (IBGE, 2016).

A influência da mídia, principalmente a televisiva, não tem fronteiras e não solicita passagem para entrar nos domicílios brasileiros. Ela é "[...] amplamente reconhecida como um elemento estratégico na produção simbólica das violências” (RIFIOTIS, 1999, p. 30) e "[...] tornou-se o veículo natural para a divulgação cotidiana de noticiários de violência e criminalidade" (BENEVIDES, 1983, p. 21).

A perplexidade é transitória; transforma-se, em pouco tempo, em sentimentos cada vez menos difusos de insegurança e medo. Trata-se da síndrome causada pela divulgação maciça, em todos os meios de comunicação, do que se convencionou chamar de 'onda da violência' (BENEVIDES, 1983, p. 19).

Ora, não se pretende com este artigo confundir a visibilidade alcançada dos eventos do "fenômeno" chamado violência com a realidade concreta deles. O objetivo proposto é mais profundo e pretende somar ao debate um viés importante da realidade social, a saber, a divulgação de notícias de violência pelos meios de comunicação no cotidiano das pessoas a partir de uma redação crítica.

Em países como o Brasil, a mídia tem um grande papel de influenciadora no modo de vida da população. Isso se deve ao fato de considerável parcela dos principais meios de comunicação serem administrados por tradicionais famílias, que representam a grande elite econômica e política. Em maio de 2011, o Ministério das Comunicações divulgou o cadastro dos proprietários de rádios e televisões no Brasil. Segundo o órgão federal, existiam no país 
291 emissoras de televisão, 3.205 de rádios e 6.186 retransmissoras comerciais. O número de políticos sócios ou diretores dessas emissoras era de 56 (quase 20\%), considerando apenas os deputados e/ou senadores; já considerando os prefeitos e vereadores, o número passava dos 200, quase $70 \%$ do total (PORTAL FOLHA, 2011).

No Estado do Paraná, pelo menos $15 \%$ das rádios registradas no Ministério das Comunicações estavam nas mãos de políticos. Os levantamentos revelaram que pelo menos 54 emissoras de rádio das 355 com registro no Governo Federal pertenciam aos políticos ou familiares. Foram identificados ex-governadores, conselheiro do Tribunal de Contas do Estado, secretários de Estado, deputados federais e estaduais, prefeitos, ex-prefeitos e vereadores. Pela legislação, um político pode ser sócio de apenas uma rádio ou televisão, mas sem exercer cargo de diretor. Apesar da proibição, a falta de fiscalização acaba por transformar o veículo de comunicação em uma potencial máquina de fazer votos. (KOLBACH, 2011). Em algumas cidades do interior do Estado do Paraná todas as rádios estavam nas mãos de políticos. Em Ivaiporã, por exemplo, as três emissoras de rádio e a única de televisão, em 2011, eram de políticos (KOLBACH, 2011).

Esses grupos regionais, donos de grandes corporações localizadas nas capitais e nas maiores cidades do interior dos Estados, acabam por direcionar, geralmente, a sua programação para assuntos de interesse desses espaços ou de nível global. Assim, praticamente, obrigam a população das pequenas cidades a consumirem as notícias de espaços fora da realidade em que vivem, inclusive quanto à violência. Portanto, esses moradores, além dos medos e das violências da sua localidade, convivem, também, com os medos e as violências de outros espaços.

Além disso, cada vez mais, os programas culturais estão sendo trocados pelo entretenimento, que, na atualidade, é representado por programas de humor, de intimidade diversos casos da vida das pessoas - e de violência. Os programas culturais, quando existem, passam em horários pouco acessíveis. De acordo com Chaui (2006, p. 21), a cultura, vista "[...] pelo prisma da criação e expressão das obras de pensamento e das obras de arte", possui três traços principais que a torna distante do entretenimento.

\footnotetext{
Em primeiro lugar, é trabalho, ou seja, movimento de criação do sentido [...]. Em segundo lugar, é a ação para dar a pensar, dar a ver, dar a refletir, a imaginar e a sentir o que se esconde sob as experiências vividas ou cotidianas [...]. Em terceiro, em uma sociedade de classes, de exploração, dominação e exclusão social, a cultura é um direito do cidadão, direito de acesso aos bens e obras culturais, direito de fazer cultura e de participar das decisões sobre a política cultural [grifo do autor] (CHAUI, 2006, p. 21)
}

Sem desmerecer as demais, a terceira é a mais relevante. A pouca ou inexistente difusão de programação de boa qualidade cultural no Brasil tem a ver com a estratificação social brasileira e capitalista. Sobre o grifo participar das decisões sobre a política cultural, não é de interesse da classe dominante que a população em geral participe da política e das decisões da vida política e econômica do País.

Logo, tudo na mídia é transformado em entretenimento, como as tragédias e os genocídios. A burguesia, considerada "culta", prefere uma classe operária "inculta", para ser controlada até na hora do "descanso". Assim, tem-se um mercado favorável à mídia, principalmente quanto ao consumo e à reprodução dos seus interesses. E o que é pior: mascara a realidade com o discurso de que todos têm, por meio da mídia, o acesso à cultura. 
Esse projeto, considerado moderno, se assentou sobre dois pilares, de acordo com Chaui (2006): regulação e emancipação. O pilar da regulação tem três princípios: o Estado (impõe a obrigação política vertical), o mercado (impõe a obrigação política horizontal individualista e antagônica) e a comunidade (obrigação política horizontal solidária). Já o pilar da emancipação tem três lógicas: a racionalidade expressiva da arte, a racionalidade cognitiva e instrumental da ciência e da técnica e a racionalidade prática da ética e do direito.

Assim, na ideia do projeto moderno, ambos se desenvolveriam harmoniosamente, ou seja, da regulação e da emancipação e da racionalização completa da vida individual e coletiva. O surgimento do capitalismo, contudo, assegurou a vitória do pilar da regulação contra o da emancipação, cada vez mais excluído. Logo, se destrói a autonomia racional do pensamento, das artes da ética e do direito (CHAUI, 2006). Nesse sentido, deve-se pensar em superar tal perspectiva e assegurar a ampliação da emancipação humana, sobretudo a partir de uma consciência coletiva e de sociabilidade positiva.

Infelizmente, considerável parte da mídia se posiciona ao lado do poder: i) econômico, onde formam, cada vez mais, por meio de fusões ou aquisições, grandes corporações que monopolizam a informação e o entretenimento, além de lutarem, a qualquer custo, pelo máximo de audiência e pela ampliação do padrão consumista; e, ii) político, que, como uma mão de duas vias, se junta ao poder econômico para ampliar seus resultados e beneficiar ambos os poderes (CURBET, 2010).

Os meios de comunicação, no mundo contemporâneo, passam a atuar, no que Paul Virilio chama de acronia e atopia (CHAUI, 2006). A acronia significa sem tempo, ausência do tempo. Já a atopia constitui a ausência de lugar, de um espaço diferenciado ou, associado à utopia, um lugar perfeito ainda inexistente. Ou seja, se perde a noção de tempo e de espaço no que é vinculado pela imprensa, conforme segue:

i) Atopia ou ausência de uma referência espacial. Os aparelhos de rádio e de televisão e a internet tornam-se um único espaço real, apagando as diferenças do espaço percebido (longe, perto, grande e pequeno). Assim, as distâncias são ignoradas e aquilo que ocorre no Japão, no Canadá ou na pequeníssima cidade de Nova América da Colina, no interior do Paraná, aparece igualmente próximo e igualmente distante.

ii) Acronia ou ausência de uma referência temporal. Os acontecimentos são narrados como se não tivessem consequências passadas, nem efeitos no futuro, ou seja, são pontos presenciais, momentâneos e sem conexão com o tempo. Eles duram apenas o tempo que for transmitido pelo meio de comunicação.

Chaui (2006), também, aborda o "simulacro" na mídia. Simulacro é oriundo da palavra latina simulacrum, que deriva de similis, que significa "semelhante". De similis temse a palavra simul, que significa "fazer junto", e o verbo simulare, que constitui algo próximo a fingir, simular. Portanto, simulacrum pode significar uma representação ou uma cópia exata, como um fingimento. Simulacrum é o simulacro. Logo, o simulacro representa a imagem de uma imagem percebida, ou seja, passa da percepção da imagem de uma coisa à sua representação e reprodução em outra imagem.

Os meios de comunicação usam e abusam dos simulacros. Eles se apropriam da imagem, tratam-na de acordo com seus interesses e representam-na e/ou reproduzem-na como

DRd - Desenvolvimento Regional em debate (ISSNe 2237-9029) 
e quando querem. Os simulacros podem ser simulados, como podem ser uma simulação do fenômeno, tentando explicá-lo. (CHAUÍ, 2006).

Segundo Silva (2004, p. 59), “[...] a irrelevância de considerações sobre a 'paranóia' da violência, apresenta como uma falha na percepção das populações urbanas, induzidas pelo tratamento dado pela mídia ao crime violento". Assim, o tratamento do:

Fenômeno como espetáculo midiático, têm mostrado que a complexidade da busca de soluções está além da procura das causas (que pode contraditoriamente, realimentar o processo) e têm mostrado também as rotulações e estereótipos que fazem recair uma culpabilização sobre os pobres (MAGALHÃES, 2009, p. 324).

A amplificação e a retroalimentação da insegurança rendem à mídia manchetes que chama a atenção, vende jornais e revistas, amplia a audiência e gera ótimos negócios (SOUZA, 2008). Isso pode ser observado na seguinte situação:

Toca o telefone na casa de uma entrevistada, e ela se mostra agitada. Vai até a janela e volta, confirmando: “É, eu vi, tem um homem lá fora! Quem será? Porque está ali parado?... O quê?... Está ali há mais de uma hora?... Não sei se é o caso de chamar a polícia...". As exclamações, o olhar pela janela, a fala alarmada, o medo [...]: quem está lá fora é seu conhecido (MAGALHÃES, 2009, p. 325).

O drama sofrido pela dona da casa, enquanto era entrevista por uma pesquisadora, se difunde, atualmente, em cidades de pequeno e de médio porte. No caso relatado, o desconhecido da dona de cada era conhecido da pesquisadora e apenas estava esperando do lado de fora. Segundo Magalhães (2009), há também uma alteração na utilização do espaço público, principalmente sua utilização à noite, ou seja, quem se desloca tem que justificar a sua presença no espaço público, antes considerado livre para circulação e uso.

Tal medo e situação de pânico podem ter origem direta nos meios de comunicação. É preciso que a universidade, sobretudo por meio das Ciências Humanas, investigue profundamente essa possibilidade. O receio do desconhecido leva as pessoas a terem esses tipos de ações. Nos estudos de Magalhães (2006, p. 326), "os entrevistados revelam temores e preocupações com a violência e ideais de moradia muito semelhantes ao de moradores de grandes metrópoles mundiais".

Obviamente que os inúmeros programas policiais e/ou os jornais dos meios de comunicação somados ao aumento significativo das ocorrências violentas em pequenas cidades - que, por conseguinte, aumenta o sentimento de pertencer a um lugar não mais seguro - transformam o modo de viver nas pequenas cidades, aproximando-o ao encontrado em cidades maiores, sobretudo as metrópoles.

A grande difusão dos programas chamados de policiais pela imprensa nacional é o reflexo dos altos índices de audiência que essa modalidade de entretenimento tem alcançado. Geralmente, são exibidos ao vivo e quando as pessoas estão em casa, horário do almoço, do jantar ou final da noite. Esses programas tratam da violência e os apresentadores aparecem, quase sempre, com utensílios, como cassetetes e algemas, e com jargões e jingles.

Um dos mais famosos na televisão brasileira é o Brasil Urgente, exibido pela Rede Bandeirantes de Televisão. Além dele, a Band apresenta o Polícia 24 horas, sendo que as cenas ocorrem "[...] sem maquiagem, atores ou ficção [...]. As câmeras fazem um registro fiel 
do trabalho das corporações nas mais variadas ações, que vão da mediação de problemas comuns até situações de confronto" (BAND, 2017). Já Record TV tem uma vasta grade de programas relacionados à temática da violência, sendo o Balanço Geral e o Cidade Alerta (RECORD, 2017) os principais programas.

No âmbito acadêmico já existem estudos sobre esses programas que se multiplicam (ou se remodelam/renovam) na imprensa nacional, como Teixeira (2002), em $A$ espetacularização do crime violento pela televisão: o caso do programa Linha Direta, e Honorat (2005), em $A$ mídia e o sentimento de insegurança: estudo de recepção sobre o programa Barra Pesada.

Em síntese, têm-se duas situações sobre a influência da mídia. A primeira, quando os casos divulgados pela imprensa encontram um solo já fértil no imaginário dos moradores de pequenas cidades violentas, sendo que nesse caso a cidade já apresenta um aumento efetivo dos casos de violência. Já a segunda situação está relacionada ao fato da percepção social da violência ser maior que a realidade, ou seja, quando os registros e/ou os casos são pequenos e efêmeros e, nesse caso, a mídia influencia diretamente na questão do medo. Essas duas situações permeiam os debates empíricos deste artigo.

O jornal já foi o principal meio de comunicação da mídia brasileira. Atualmente, muitos se modernizaram, entrando nas plataformas de internet ou lançando apenas versões digitais. A abordagem de assuntos associados à violência e à insegurança pelos meios de comunicação, principalmente os jornais, não é recente no contexto brasileiro. De acordo com Benevides (1983, p. 21), houve uma mudança na atitude da imprensa tradicional brasileira especificamente a jornalística - em relação à própria violência no início da década de 1980: "passaram a destacar manchetes em primeira página e a dedicar amplo espaço aos temas de delinqüência violenta".

O exemplo do Jornal do Brasil é o mais explícito: em janeiro de 1981, o jornal passou a publicar uma rubrica especial, intitulada Violência, no alto da folha, com o mesmo destaque das tradicionais rubricas Política e Governo, Internacional, Esporte, etc. [...]. O Estado de S. Paulo [...] passou a reservar maior espaço ao tema [...]. A Folha de S. Paulo editou cadernos especiais sobre violência [...]. O Jornal da Tarde [...] especializou-se no acompanhamento diário dos "casos especiais" (BENEVIDES, 1983, p. 21-22).

Tal contexto se expandiu para os demais jornais brasileiros, inclusive localizados em cidades do interior. Naquele momento, as notícias quase que exclusivamente se dedicavam aos eventos que ocorriam nas metrópoles de São Paulo e do Rio de Janeiro, com algumas menções aos fatos de Belo Horizonte. Pode-se dizer que naquele momento, há três décadas passadas, surgia o embrião desse tipo de cobertura jornalística, na esfera do jornal, tão difundida ao longo do século XXI. Na porção seguinte, a redação transita pela parte empírica.

\section{AS NOTÍCIAS DE VIOLÊNCIA NO NORTE CENTRAL PARANAENSE}

A utilização de notícias de jornais, a partir de um olhar crítico, é uma ferramenta complementar importante para compreender a realidade de um determinado local ou de uma 
região. Neste artigo, optou-se por abordar a modalidade de jornal impresso que contempla um contexto regional. Para isso, utilizou-se como fonte o principal jornal, de abrangência regional, da região de Maringá (PR), O Diário do Norte do Paraná. Ele é o jornal de maior influência na região de Maringá, circulando em mais de sessenta municípios e com média de 15 mil unidades diárias, sendo 12 mil assinantes. No começo de 2011, o jornal se expandiu para Londrina e região, apenas em formato online.

O jornal O Diário do Norte do Paraná foi fundado em 29 de junho de 1974 em Maringá, no Norte paranaense, onde se mantém como sede até os dias atuais. Ele pertence ao Grupo $O$ Diário e é filiado à Associação Nacional de Jornais (ANJ), Word Association of Newspapers (WAN), Newspaper Association of America, Associação dos Diários do Interior do Brasil (ADI), Associação dos Diários do Interior do Paraná (ADI-PR) e ao Instituto Verificador de Circulação (IVC).

O levantamento no jornal O Diário do Norte do Paraná ocorreu presencialmente, sendo catalogadas as notícias relacionadas à insegurança, à violência e às questões sociais em pequenas cidades. Nesse levantamento, foram desconsideradas as cidades que não são consideradas pequenas (Londrina, Maringá, Apucarana, Arapongas, Cambé, Sarandi, Ibiporã e Rolândia) e as pequenas cidades de Marialva, Mandaguaçu, Paiçandu e Tamarana devido à proximidade com Maringá e/ou com Londrina, pois comprometeriam os resultados, uma vez que são divulgadas notícias de violência e insegurança nessas cidades com muita frequência.

O levantamento totalizou 714 notícias vinculadas à temática, em 119 municípios diferentes. A Figura 2 apresenta a média, por mês, de notícias encontradas sobre a temática entre 2001 e 2011. A opção por apresentar o gráfico dessa forma, ao invés da quantidade exata encontrada em casa mês ou ano, se deve à necessidade de mostrar com maior clareza os momentos em que existiram as maiores médias, por mês, de notícias acerca da violência e da insegurança em pequenas cidades. Os anos se mantiveram próximos à média de quase seis notícias por mês, sendo que é possível observar que em dois momentos o jornal passou a divulgar mais notícias sobre o tema.

Figura 2 - O Diário do Norte do Paraná. Média de notícias, por mês, 2001-2011

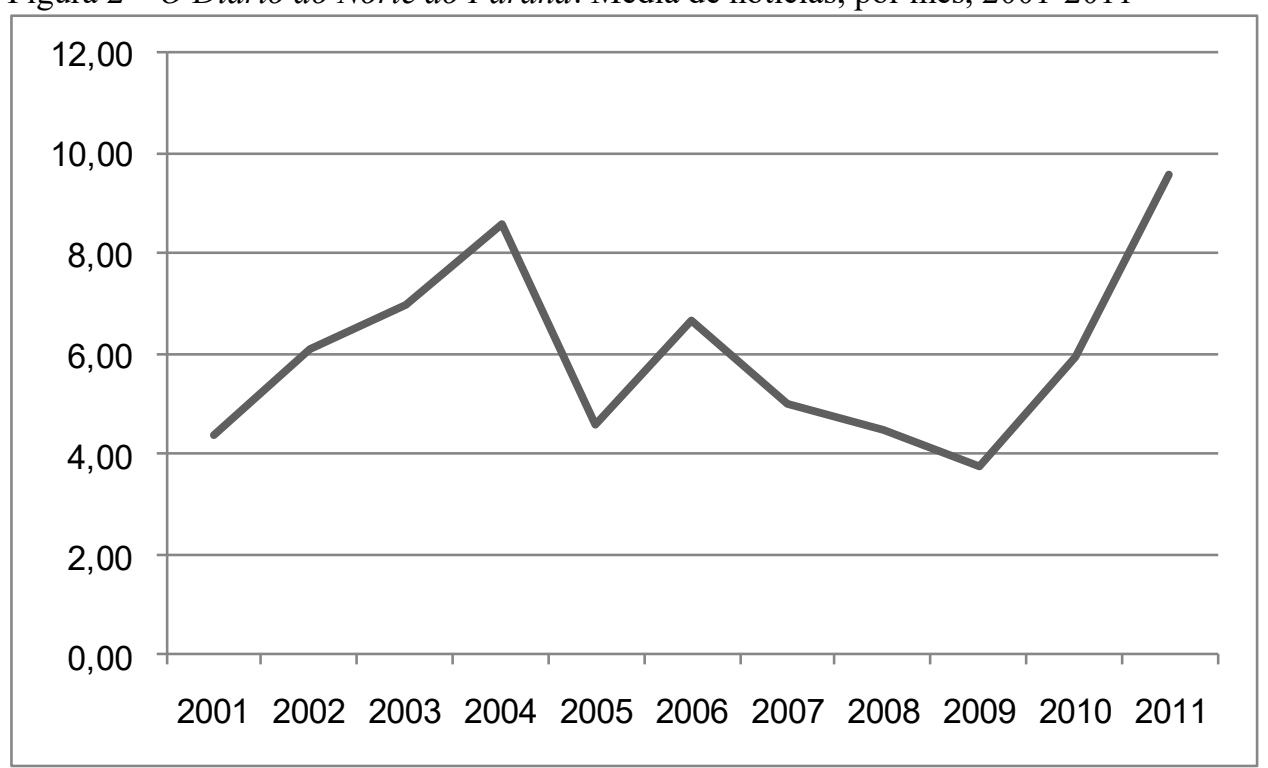

Fonte: Elaboração própria, com base nos dados da pesquisa 
No primeiro momento, de 2001 a 2004, existia no jornal um caderno regional. Sendo assim, houve no período um olhar maior sobre os acontecimentos nas pequenas cidades da região. O ano de 2004 apresentou a maior quantidade, com 103 reportagens. Contudo, com a extinção do caderno, a média de notícias passou a cair, chegando, em 2009, ao pior patamar: 3,75 notícias por mês ou 45 no ano. Em 2011, último ano liberado para consulta, havia, dentro do caderno principal, um espaço de uma página para as notícias das cidades pequenas da região. Assim, a quantidade de notícias encontradas nos últimos dois anos revelou um aumento nos eventos violentos em pequenas cidades da região. $\mathrm{O}$ ápice na média foi no ano de 2011: 67 notícias em sete meses, gerando uma média de quase dez notícias por mês. A Figura 3 apresenta a proporção, em porcentagem, de cidades, por quantidade de notícias, considerando o universo total de 119 municípios.

A grande maioria, com quase $40 \%$ dos municípios, apresentou apenas uma notícia divulgada no período. Isso é resultado de notícias garimpadas em outros meios de comunicação, referindo-se, portanto, a municípios de outros Estados, principalmente São Paulo. Os maiores estratos correspondem a quase $27 \%$ das cidades, sendo que quase $18 \%$ delas tiveram entre cinco e 15 notícias no período e pouco mais de $9 \%$ foram destaque em mais de 15 reportagens. Esse universo, especificamente, corresponde às pequenas cidades da região Norte Central paranaense.

Figura 3. O Diário do Norte do Paraná. Proporção de municípios por quantidade de notícia(s)

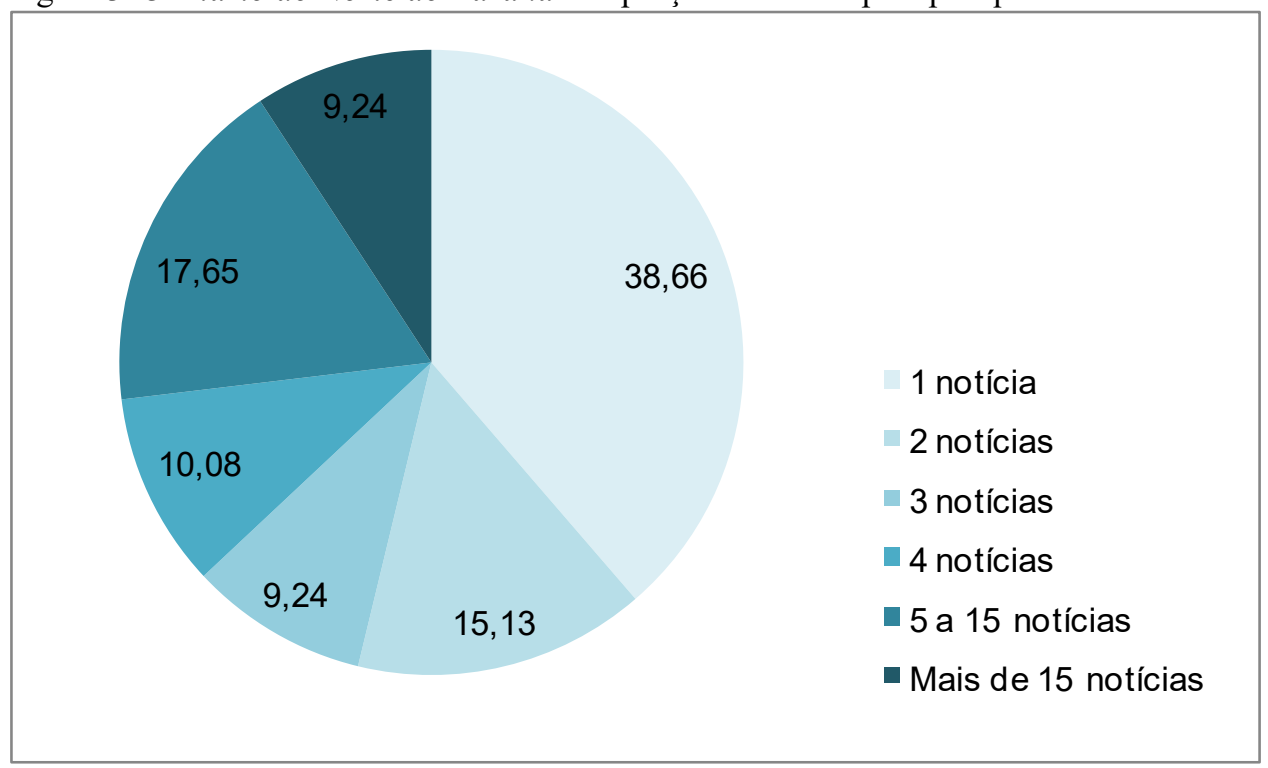

Fonte: Elaboração própria, com base nos dados da pesquisa

O Quadro 1 exibe as pequenas cidades da região Norte Central paranaense que contemplaram mais de $1 \%$ de notícias no período de 2001 a 2011. Elas representam um estrato de 23 municípios (19,3\% do total, $29,1 \%$ do total de municípios da região e $34,3 \%$ das pequenas cidades da região) que somam $70,4 \%$ de todas as notícias encontradas no período. 
Quadro 1. O Diário do Norte do Paraná. Proporção de notícias, por cidades

\begin{tabular}{|l|l|c|c|}
\hline \multicolumn{1}{|c|}{ Pos. } & \multicolumn{1}{|c|}{ Município } & População urbana (2010) & \% de notícias \\
\hline 01 & Mandaguari & 30.934 & 11,69 \\
\hline 02 & Nova Esperança & 24.323 & 6,88 \\
\hline 03 & Astorga & 22.559 & 6,74 \\
\hline 04 & Colorado & 21.005 & 5,36 \\
\hline 05 & Santa Fé & 9.232 & 4,68 \\
\hline 06 & Floresta & 5.470 & 4,40 \\
\hline 07 & Jandaia do Sul & 18.331 & 3,71 \\
\hline 08 & Paranacity & 9.469 & 3,44 \\
\hline 09 & Iguaraçu & 3.559 & 3,03 \\
\hline 10 & Presidente Castelo Branco & 4.197 & 2,34 \\
\hline 11 & Munhoz de Mello & 2.974 & 2,20 \\
\hline 12 & Nossa Senhora das Graças & 3.182 & 2,06 \\
\hline 13 & Engenheiro Beltrão & 12.278 & 1,93 \\
\hline 14 & Ivaiporã & 27.438 & 1,51 \\
\hline 15 & Ângulo & 2.253 & 1,38 \\
\hline 16 & Ivatuba & 2.294 & 1,38 \\
\hline 17 & Barbosa Ferraz & 9.581 & 1,10 \\
\hline 18 & Doutor Camargo & 5.109 & 1,10 \\
\hline 19 & Floraí & 4.472 & 1,10 \\
\hline 20 & Itambé & 5.674 & 1,10 \\
\hline 21 & Lobato & 4.105 & 1,10 \\
\hline 22 & São João do Ivaí & 8.874 & 1,10 \\
\hline 23 & São Jorge do Ivaí & 4.781 & 1,10 \\
\hline Fon & & \\
\hline
\end{tabular}

Fonte: IBGE (2010) e dados da pesquisa

A pequena cidade de Mandaguari apareceu na primeira posição com quase $12 \%$ do total de notícias sobre violência e insegurança. Na lista apresentada, ela é a maior demograficamente, com quase 31 mil habitantes. A segunda colocada, Nova Esperança, ficou bem atrás com quase $7 \%$ do total de notícias. Entre as cidades demograficamente menores, três apresentavam menos de três mil habitantes: Munhoz de Mello, de 2.974 habitantes (IBGE, 2010), com 2,2\% das notícias, e Ângulo, de 2.253 moradores (IBGE, 2010) e Ivatuba, de 2.294 residentes (IBGE, 2010), com 1,38\% cada uma.

A Figura 4 espacializa os resultados acerca da quantidade de notícias, por estratos, encontradas nas pequenas cidades do Norte Central paranaense. É fundamental reforçar que 12 municípios foram desconsiderados devido ao tamanho demográfico e/ou a influência metropolitana direta de Londrina e/ou Maringá. 
Figura 4. Mesorregião Norte Central paranaense. Quantidade de notícias por pequenas cidades

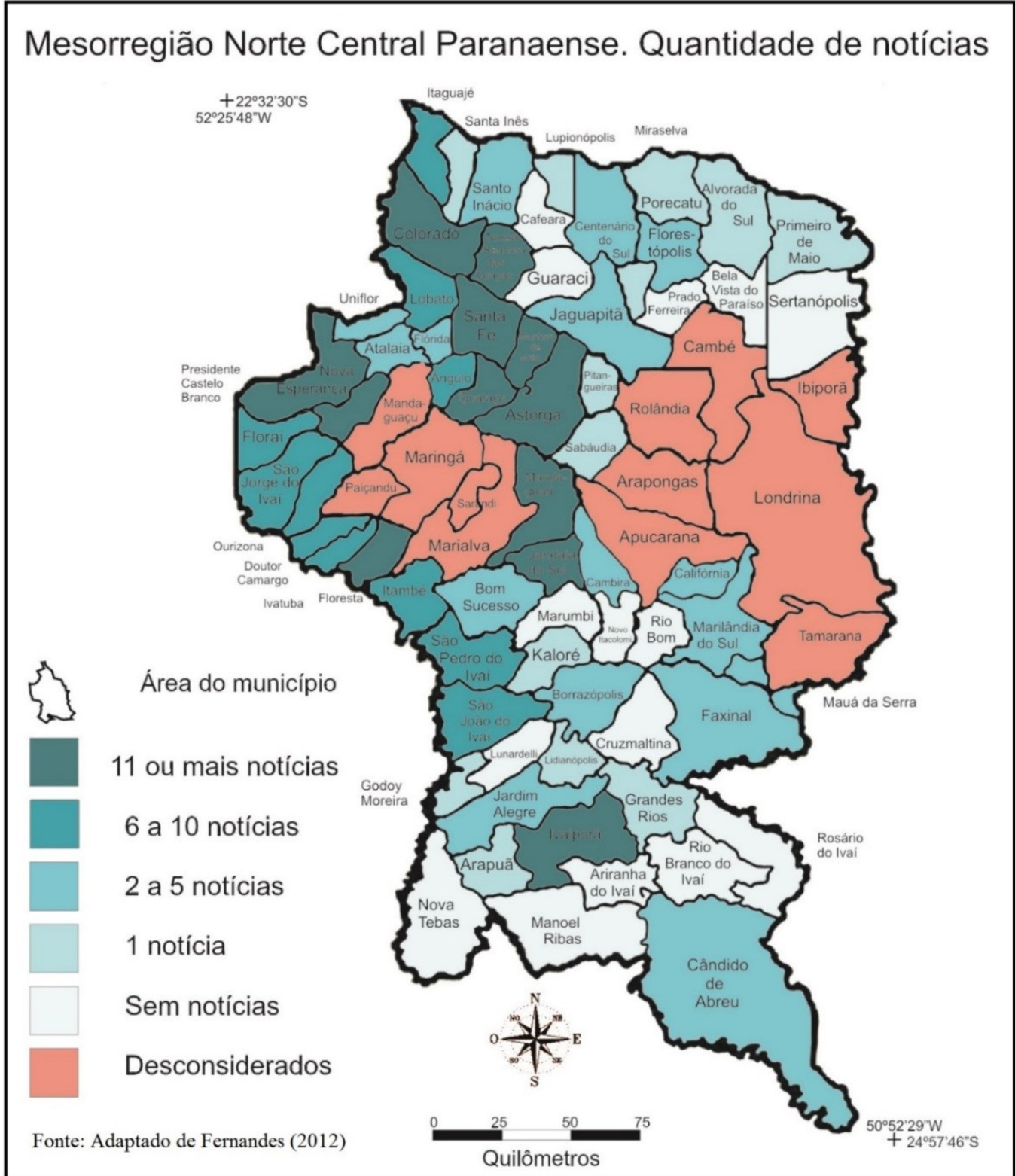

Fonte: Adaptado de Fernandes (2012).

Entre as pequenas cidades, $22,4 \%$ não foram citadas ao longo dos dez anos de reportagens levantadas. Será que nessas localidades não existem ocorrências de violência? $\mathrm{Ou}$ será que não há o interesse do jornal em divulgar tais fatos? Enquanto os moradores das pequenas cidades são bombardeados diariamente com notícias e ações realizadas em Maringá, Curitiba, São Paulo e outras cidades maiores, os acontecimentos das suas cidades não passam de detalhes insignificantes para a mídia regional. Portanto, há um diálogo com a base teórica, uma vez que os meios de comunicação usam de simulacros (CHAUÍ, 2006) nesses casos, já que, de acordo com seus interesses, representam e/ou reproduzem o fenômeno como querem.

Já em 77,6\% das pequenas cidades da região Norte Central paranaense aconteceram eventos de violência ou insegurança noticiados pelo jornal. Entre elas, 25\% apresentaram apenas uma notícia divulgada e $31 \%$ tiveram a divulgação de duas a cinco reportagens. Em 
contrapartida, em $23 \%$ das pequenas cidades foram encontradas mais de 11 notícias divulgadas pelo jornal.

O Quadro 2 apresenta a proporção de notícias por teor de acontecimentos. É possível perceber que situações cotidianamente vinculadas às áreas metropolitanas também ocorrem em municípios polarizados por pequenas cidades. Concretamente, a maioria desses eventos está relacionada aos furtos, aos roubos e aos homicídios (ou tentativa deles) que podem ser resultados de brigas, disputas por venda e consumo de drogas, etc.

Quadro 2. O Diário do Norte do Paraná. Proporção de notícias por teor de acontecimentos

\begin{tabular}{|l|r|}
\hline Teor & \% \\
\hline Roubo e furto (ou tentativa) & 21,85 \\
\hline Homicídio (ou tentativa) & 17,37 \\
\hline Prisões & 8,54 \\
\hline Roubo e furto (ou tentativa) de bancos, lotéricas e caixas eletrônicos & 7,00 \\
\hline Roubo e furto (ou tentativa) de ônibus & 5,74 \\
\hline Violência doméstica e violência contra mulher & 5,04 \\
\hline Solicitação de segurança pública e ausência de efetivo e de infraestrutura & 3,78 \\
\hline Fuga (ou tentativa), rebeliões e resgate de presos & 3,64 \\
\hline Tráfico, consumo e apreensão de drogas e produtos ilícitos & 3,08 \\
\hline Exploração sexual e pedofilia & 2,96 \\
\hline Brigas, espancamentos e pedradas que não resultaram em mortes & 2,94 \\
\hline Agentes públicos da segurança envolvidos crimes, como corrupções e homicídios & 2,52 \\
\hline Estupro (ou tentativa) & 2,38 \\
\hline Estelionato (ou tentativa) & 2,38 \\
\hline Latrocínio & 2,10 \\
\hline Políticos ou servidores públicos afastados por corrupção & 1,96 \\
\hline Ossadas e cadáveres encontrados & 1,26 \\
\hline Sequestro & 1,26 \\
\hline Outras & 4,20 \\
\hline Fonte: Elabraço própra com & \\
\hline
\end{tabular}

Fonte: Elaboração própria, com base nos dados da pesquisa

Os roubos, os furtos e os homicídios (ou a tentativa deles) somaram quase $40 \%$ de todas as notícias encontradas. Esse patamar passa de $52 \%$ considerando-se os roubos e furtos (ou tentativas) de bancos, lotéricas, caixas eletrônicos e ônibus. A violência doméstica, incluindo a contra a mulher, apareceu com 5\% das reportagens e o tráfico, consumo e apreensões de drogas ou produtos ilícitos com 3\%. Portanto, articulando os resultados expostos nesta parte, é possível perceber que a percepção de Benevides (1983), quanto à divulgação cotidiana de noticiários de violência e criminalidade por parte da mídia se mantem desde a década de 1980. A diferença é que tal situação ultrapassou as barreiras metropolitanas e tem atingindo, cada vez mais, espaços não metropolitanos, sobretudo das pequenas cidades.

\section{AS TAXAS DE HOMICÍDIOS NO NORTE CENTRAL PARANAENSE}

A partir das taxas de homicídios apresentadas por Fernandes (2017) é possível comparar e promover reflexões acerca desses dados com os fatos divulgados pela mídia no 
Norte Central paranaense. Segundo Fernandes (2017), a maioria dos municípios que compõem o Norte do Estado do Paraná vive em estado de emergência, com epidemias de violência, já que superam a taxa de homicídios tolerada pela Organização das Nações Unidas (ONU). A Figura 5 apresenta os municípios do Norte Central paranaense por estrato de taxa de homicídio, em grupo de cem mil pessoas, entre 1996 e 2013.

Figura 5. Mesorregião Norte Central paranaense. Taxa de homicídio, 1996 a 2013

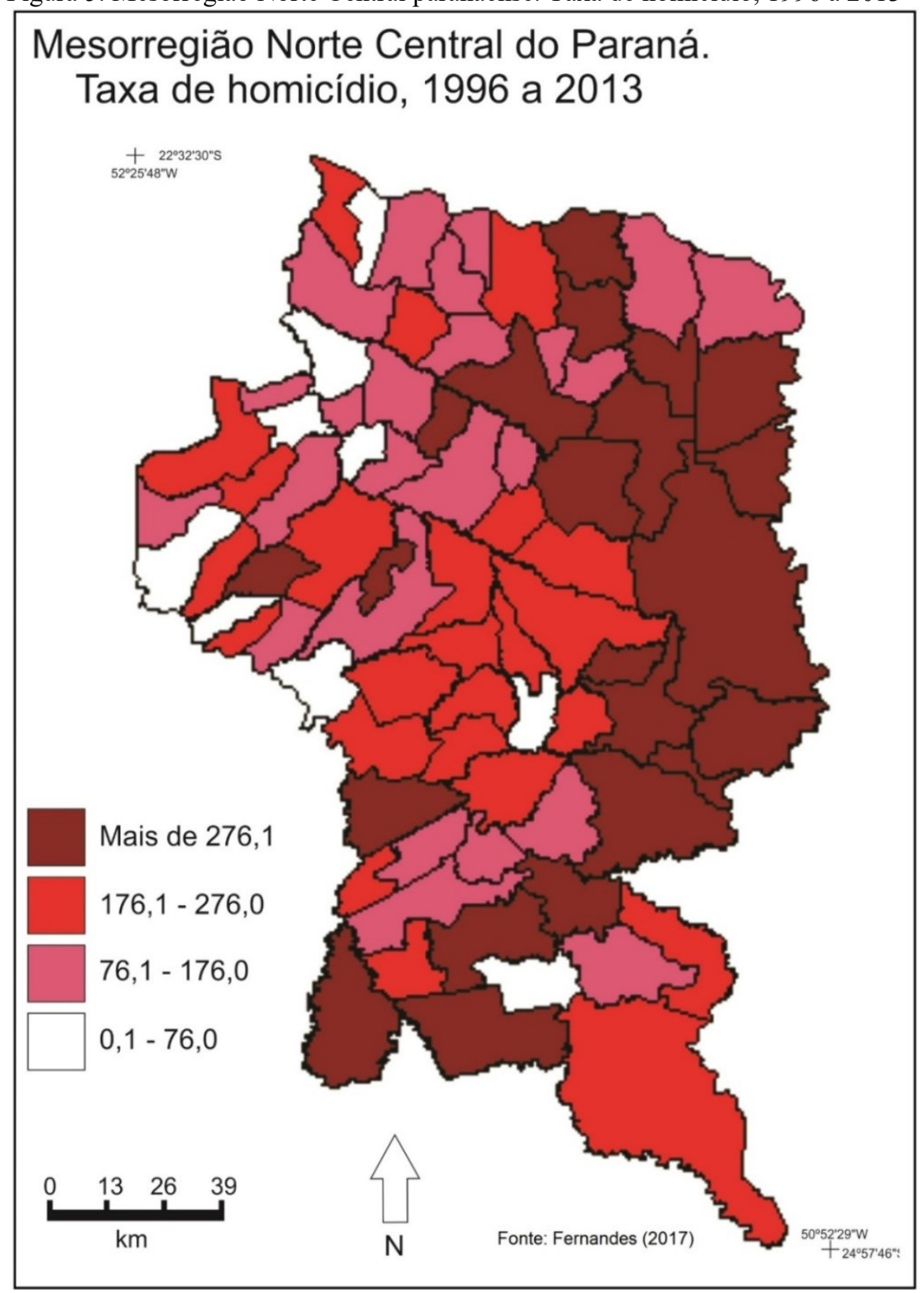

Fonte: Adaptado de Fernandes (2017).

Apenas nove municípios (11\%) possuem taxas consideradas "baixas" de homicídios. É importante ressaltar que o ideal, ainda que em utopia, é a total ausência de homicídios. Apesar disso, $28 \%$ dos municípios do Norte Central possuem taxas inferiores ao tolerado pela ONU. É possível perceber que os municípios com maiores taxas de homicídios estão no Leste e no 
Sul da região, com exceção de Paiçandu e Sarandi que estão a Oeste da região e dentro da Região Metropolitana de Maringá.

O Quadro 3 lista os municípios que possuem as maiores taxas de homicídios na região Norte Central paranaense, para cada grupo de cem mil habitantes, no período de 1996 a 2013, sendo que todos apresentaram indicadores com, no mínimo, o dobro do tolerado pela ONU para o período.

Quadro 3: Norte do Paraná. Municípios com maiores taxas de homicídios, 1996-2013

\begin{tabular}{|l|l|c|c|}
\hline Pos. & \multicolumn{1}{|c|}{ Município } & População total (2010) & Taxa de homicídio \\
\hline 01 & Nova Tebas & 7.398 & 648,82 \\
\hline 02 & Florestópolis & 11.222 & 623,77 \\
\hline 03 & Tamarana & 12.262 & 513,78 \\
\hline 04 & Sarandi & 82.847 & 502,13 \\
\hline 05 & Cambé & 96.733 & 473,47 \\
\hline 06 & São João do Ivaí & 11.525 & 468,55 \\
\hline 07 & Mauá da Serra & 8.555 & 455,87 \\
\hline 08 & Sertanópolis & 15.638 & 434,84 \\
\hline 09 & Londrina & 506.701 & 415,43 \\
\hline 10 & Ibiporã & 48.198 & 400,43 \\
\hline 11 & Jaguapitã & 12.225 & 392,64 \\
\hline 12 & Grandes Rios & 6.625 & 392,45 \\
\hline 13 & Rolândia & 57.862 & 354,29 \\
\hline 14 & Manoel Ribas & 13.169 & 334,12 \\
\hline 15 & Faxinal & 16.314 & 331,00 \\
\hline 16 & Porecatu & 14.189 & 317,15 \\
\hline
\end{tabular}

Fonte: Adaptado de Fernandes (2017)

Entre os municípios listados, $11(69 \%)$ são polarizados por pequenas cidades. Londrina, que demograficamente é a maior cidade do interior do Estado do Paraná com mais de meio milhão de habitantes, aparece na nona posição. Na lista é possível perceber que três municípios possuem menos de dez mil habitantes: Nova Tebas, Mauá da Serra e Grandes Rios. O município demograficamente menor é Grandes Rios, de 6,6 mil habitantes (IBGE, 2010), na décima segunda posição. Nova Tebas e Florestópolis, estudados em Fernandes (2012), são os líderes do ranking, possuindo taxas $256 \%$ superiores aos valores tolerados.

Por isso, a violência em pequenas cidades do Norte Central do Paraná não representa uma anomalia, como muitas vezes é tratada nos meios acadêmicos. A análise temporal no período de 1996 a 2013 demonstra que os homicídios mantêm relativa constância no contexto municipal e regional, com picos destoantes em alguns casos.

Associando o levantamento de notícias com as taxas de homicídios, têm-se quatro reflexões principais. Na primeira, o município de Nova Tebas, líder do ranking, enfrentou homicídios em 14 anos (77,7\%) da série histórica, apresentando exceção em 1997, 1998, 2007 e 2012, e mesmo assim não apareceu com nenhuma reportagem no levantamento realizado no jornal O Diário do Norte do Paraná. Na segunda, o município de Florestópolis, segundo colocado, apresentou entre duas e cinco reportagens no levantamento realizado no jornal, ainda assim, esse valor é muito baixo perto da altíssima taxa de homicídio que o município possui. A terceira reflexão é sobre São João do Ivaí, sexto colocado no ranking de homicídios entre os 79 que compõem a região Norte Central paranaense, que possui entre seis e dez reportagens, valor baixo perto da proporção de homicídios indicada. Finalmente, como última 
reflexão, é possível aferir que nenhum dos municípios que aparece com as maiores quantidades de notícias levantadas no jornal $O$ Diário do Norte do Paraná está no ranking de taxas de homicídios.

Já as reflexões dessa articulação entre as duas partes empíricas deste artigo e a base teórica e metodológica que se assenta, caminham por três leituras importantes. Inicialmente, é fato que há uma ampliação da difusão de insegurança e medo nas cidades da região Norte Central paranaense a partir da mídia, dialogando, teoricamente, com Benevides (1983) e Fernandes (2012). Trata-se, então, da síndrome causada pela divulgação maciça de violência, prevista por Benevides (1983).

Depois, na segunda reflexão, há uma falha na percepção pelo tratamento dado pela mídia ao crime violento, pensado por Silva (2004) e Chaui (2006), ou seja, o tratamento da violência é seletivo, espacialmente e socialmente, sendo que neste artigo abordou-se a leitura espacial. Logo, algumas cidades têm os seus casos amplamente divulgados, enquanto outras são ignoradas, demonstrando o interesse seletivo por alguns espaços. Finalmente, como terceira reflexão, tem-se que as taxas de homicídios mostraram que algumas cidades vivem com constância de casos, sendo que estes sequer são divulgados pela mídia seletiva - nos estudos de Fernandes (2017) é possível entender com maior profundidade esse espectro rondando os espaços das pequenas cidades.

\section{CONSIDERAÇÕES FINAIS}

A violência e a insegurança se disseminaram na sociedade brasileira se tornando um discurso comum na mídia. Isso tem, cada vez mais, atingindo espaços antes não contemplados, como das pequenas cidades e das áreas rurais. Nesse sentido, a construção do imaginário das cidades é resultado de uma produção articulada e não aleatória de grupos de agentes produtores, inclusive a própria mídia. Por isso, este artigo demonstrou a abordagem da violência pela mídia nas pequenas cidades da região Norte Central do Paraná à luz de uma leitura teórica e metodológica crítica. A partir disso e de uma comparação com as taxas de homicídios, foi possível aferir algumas reflexões sobre o papel da mídia acerca da violência e da insegurança.

É fundamental ressaltar que contemplar os fatos divulgados pela mídia, em correspondência com os resultados empíricos, gerou, ao mesmo tempo, situações antagônicas: propagadora do medo, da insegurança e da violência versus difusora de casos não contemplados pelos órgãos estatais. Os resultados empíricos dialogaram nesse sentido, demonstrando casos em que a mídia destacou espaços não contemplados pelos órgãos públicos de estatísticas e, concomitantemente, casos em que a mídia produziu um simulacro ou simplesmente ignorou espaços das pequenas cidades em detrimento de cidades maiores.

O simulacro, por sua vez, corresponde à imagem de uma imagem percebida, ou seja, passa da percepção da imagem de uma coisa à sua representação e reprodução em outra imagem. Os meios de comunicação abusam desses simulacros, se apropriando da imagem, tratam-na de acordo com seus interesses, como foi possível constatar no levantamento 
realizado em um jornal impresso que seleciona casos e espaços contemplados para a divulgação, enquanto outros são olvidados.

No caso do jornal $O$ Diário do Norte do Paraná, o enfoque é praticamente voltado aos acontecimentos de Maringá, Sarandi, Marialva e Paiçandu. Apenas os eventos que ganharam maiores proporções nas demais cidades foram destacados. Além disso, devido à influência dos grandes meios de comunicação, foram encontradas notícias irrelevantes recorrentes de cidades do interior de São Paulo, enquanto aquilo que acontecia dentro da própria região de cobertura do jornal foi negligenciado, como os inúmeros homicídios de Nova Tebas.

Em contrapartida, os dados oficiais disponibilizados pelos órgãos públicos, em sua maioria, não contemplam a realidade urbana em totalidade. No caso do Estado do Paraná, os dados divulgados pelo Governo Estadual para os municípios não tratam de dados de furtos, roubos, sequestros, entre outras violências em pequenas cidades. Entre os temas das reportagens levantadas, os roubos e os furtos (ou tentativa) apareceram em primeiro lugar. Assim, embora o Estado não divulgue as informações, a mídia contribuiu no sentido de divulgar esse cenário.

Então, as principais motivações deste artigo estiveram vinculadas à preocupação com a materialização da violência em espaços das pequenas cidades e como isso foi abordado pela mídia regional. É um anseio de entender como a mídia atuou diante desse tema. Ainda que exista uma série de questionamentos acerca do conceito de violência, sua interpretação subjetiva e de senso comum, o levantamento de dados revelou que os moradores de diversas cidades do Norte do Estado do Paraná convivem com uma realidade desagradável e preocupante: homicídios constantes. Porém, nem sempre eles aparecem na mídia, gerando uma "confusão" entre a realidade dessas localidades (casos de violência versus difusão de espaços tranquilos e seguros) e os simulacros construídos (metrópoles violentas e inseguras versus pequenas cidades estigmatizadas, sobretudo àquelas nas bordas metropolitanas).

Articulando isso com os resultados alcançados neste artigo, tem-se, por exemplo, que o município com maior taxa de homicídio, Nova Tebas, possui indicador 56\% maior que o de Londrina (20 lugar), o maior demograficamente do Norte Central do Estado do Paraná. Além disso, Mandaguari, líder em notícias divulgadas pela imprensa, tem taxa de homicídio bem inferior do que municípios que nem aparecem na lista de notícias divulgadas, como, por exemplo, Sertanópolis, que possui uma alta taxa de homicídio e sequer nenhuma notícia publicada no jornal.

Apesar dos dados mostrarem que diversos municípios convivem com uma constância de homicídios, os casos não são, geralmente, noticiados pela mídia regional. A maioria dos municípios, como apresentado, ficaram com poucas reportagens, em um período de dez anos de levantamento. Por isso, como fechamento deste artigo e, concomitantemente, como abertura para futuras pesquisas, há muito que se fazer pelos municípios do Norte do Paraná, seja na esfera das políticas públicas, seja na esfera da academia. Nesse sentido, há necessidade da universidade ampliar o debate acadêmico para esses espaços, publicando materiais sobre isso e contribuindo, assim, com a realidade social em totalidade. Assim, será possível entender e compreender, cada vez mais, as pequenas cidades e os fenômenos sociais contemporâneos que atingem esses espaços, como a ausência de sociabilidade, a violência, a insegurança e a globalização. 


\section{REFERÊNCIAS}

BAND, Rede Bandeirantes. Programa Polícia 24 horas. 2017. Disponível em:

$<$ http://noticias.band.uol.com.br/policia24h/o-programa.asp>. Acesso em: 22 ago. 2017.

BAUMAN, Z. Confiança e medo na cidade. Tradução de Eliana Aguiar. Rio de Janeiro: Jorge Zahar Ed., 2009.

BENEVIDES, M. V. Violência, povo e política. São Paulo: CEDEC/Brasiliense, 1983. v. 1.

CHAUI, M. Simulacro e poder. São Paulo: Editora Fundação Perseu Abramo, 2006.

CURBET, J. La inseguridad ciudadana ha cambiado nuestras vidas. In: Carajillo de la ciudad, 2010. Disponível em: <http://www.cafedelasciudades.com.ar/carajillo/6_art2.htm> Acesso em: 21 ago. 2017.

ENDLICH, A. M. Pensando os papéis e significados das pequenas cidades do Noroeste do Paraná. 505 f. 2006. Tese (Doutorado) - Universidade Estadual Paulista - Faculdade de Ciências e Tecnologia. Presidente Prudente, 2006.

FEGHALI, J.; MENDES, C.; LEMGRUBER, J. Reflexões sobre a violência urbana: (In)segurança e (Des)esperanças. Rio de Janeiro: Mauad X, 2006.

FERNANDES, P. H. C. Sociabilidade e sentimento de insegurança urbana em pequenas cidades: o Norte do Paraná. 2012. Dissertação (Mestrado) - Curso de Geografia, Centro de Ciências Humanas, Letras e Artes, Universidade Estadual de Maringá, Maringá (PR), 2012.

. Um espectro ronda as pequenas cidades: o aumento da violência e da insegurança objetiva. 2017. 525 p. Tese (Doutorado) - Curso de Geografia, Centro de Ciências Humanas, Letras e Artes, Universidade Estadual de Maringá, Maringá (PR), 2017.

GOES, E. M.; SPOSITO, M. E. B. A insegurança e as novas práticas espaciais em cidades brasileiras. Scripta Nova: Revista Eletrónica de Geografia y Ciencias sociales, v. 18, n. 493(54), p. 1-16, 2014.

HONORAT, B. A. A mídia e o sentimento de insegurança: estudo de recepção sobre o programa Barra Pesada. 2005. Dissertação (Mestrado em Sociologia), Programa de PósGraduação em Sociologia (PPG-SOL) da Universidade de Brasília (UnB). Brasília, 2005.

IBGE (Instituto Brasileiro de Geografia e Estatística). Censo Demográfico 2010. Disponível em: < http://www.censo2010.ibge.gov.br/resultados_do_censo2010.php> Acesso em: 21 ago. 2017.

Pesquisa Nacional por Amostra de Domicílios (PNAD). Rio de Janeiro, 2016.

KOLBACH, K. Políticos são donos de 15\% das rádios no PR. Portal Gazeta do Povo. 2011. Disponível em: <http://www.gazetadopovo.com.br/vidapublica/conteudo.phtml?id=1136363> Acesso em: 20 ago. 2017. 
LEFEBVRE, H. O direito à cidade. Tradução de Rubens Eduardo Frias. São Paulo: Centrauro, 2001.

MAGALHÃES, N. Significados de violência em abordagem da mensagem televisiva. In: Sociologias, Porto Alegre, n. 21, p. 318-343, jan./jun. 2009.

MAGRINI, Maria Angélica de Oliveira. Vidas em enclaves. Imaginário das cidades inseguras e fragmentação socioespacial em contextos não metropolitanos. 2013. Tese (Doutorado) - Universidade Estadual Paulista (Unesp). Presidente Prudente, 2013.

PORTAL FOLHA. Cadastro revela políticos donos de rádios e Tvs no país. 2011. Disponível em: <http://www1.folha.uol.com.br/poder/922320-cadastro-revela-politicosdonos-de-radio-e-tvs-no-pais.shtml> Acesso em: 21 ago. 2017.

RECORD, RecordTV. Programas. 2017. Disponível em: <http://recordtv.r7.com/programas > Acesso em: 22 ago. 2017.

RIFIOTIS, T. Violência policial e imprensa: o caso da Favela Naval. In: São Paulo em perspectiva. São Paulo, v. 13, n. 4, p. 28 a 41, out./dez. 1999.

SANTOS, M. Entrevista: O sonho obriga o homem a pensar. Boletim UFMG, Belo Horizonte, v. 25, n. 1229, 1999.

SILVA, L. A. M. Sociabilidade violenta: por uma interpretação da criminalidade contemporânea no Brasil urbano. Sociedade e Estado, Brasília, v. 19, n. 1, p. 53-84, jan./jun. 2004.

SOUZA, M. L. Fobópole: o medo generalizado e a militarização da questão urbana. Rio de Janeiro: Bertrand Brasil, 2008.

TEIXEIRA, A. N. A espetacularização do crime violento pela televisão: o caso do programa Linha Direta. 2002. Dissertação (Mestrado) - Universidade Federal do Rio Grande do Sul. Instituto de Filosofia e Ciências Humanas. Programa de Pós-Graduação em Sociologia. Porto Alegre: UFRGS, 2002.

\section{Artigo recebido em: 25/08/2017}

Artigo aprovado em: 14/10/2017 